\title{
DA ITÁLIA AO JAPÃO: UM ESTUDO SOBRE A MIGRAÇÃO NO BRASIL E OS SEUS MEIOS DE COMUNICAÇÃO ENTRE O FINAL DO SÉCULO XIX E O INÍCIO DO SÉCULO XXI
}

\author{
Luiz Otávio Costa ${ }^{1}$ \\ Marili Peres Junqueira²
}

RESUMO: O presente artigo é uma reflexão sobre o fenômeno migratório e sua relação com os meios de comunicação que os migrantes utilizam, notadamente pelos grupos étnicos italiano no Brasil e nipo-descendente (Brasil-Japão). A influência que os meios de comunicação exercem sobre a identidade dos grupos envolvidos e sua relação no processo de distanciamento de sua terra de origem, além da relação cultural envolvida que são fundamentais para a análise realizada. Desta forma, visamos dar visibilidade a cultura e os meios de comunicação de grupos étnicos distintos e em diferentes momentos históricos - final do século $X I X$, final do século XX e início do século XXI, que aparentemente não teriam características comuns, mas apresentam iterações e processos semelhantes como demonstrado. Tal análise foi possível a partir da teoria de Bourdieu que toma os meios de comunicação (jornais, cartas e meios de comunicação on-line) como uma estrutura estruturada para se perceber a estrutura estruturante das sociedades.

PALAVRAS-CHAVE: Migração. Meios de Comunicação. ItáliaBrasil-Japão.

1 Docente da Escola São Pio X do Estado de Minas Gerais em História e Mestre em Ciências Sociais pela Universidade Federal de Uberlândia.

2 Docente da Universidade Federal de Uberlândia (UFU), ligada ao Instituto de Ciências Sociais e ao Programa de Pós-Graduação em Ciências Sociais (INCIS/PPGCS), e Doutora em Sociologia pela UNESP-Araraquara/SP. 
ABSTRACT: This present article is a reflection on the migratory phenomenon and its relation to the means of communication used by migrants, notably by the ethnic Italian group in Brazil and also the Japanese-descendant group (Brazil-Japan). In addition, the influence of the means of communication on the identity of the groups involved and its relation in the separation process from their original land as well as the cultural relation involved were considered fundamental for the performed analysis. Thereby, we aim at giving visibility to the culture and means of communication from distinct ethnic groups in different historical moments - end of the 19th and the 20th centuries and beginning of the 21st century - points that would not have common characteristics apparently, but they present repetitions and similar processes as demonstrated. Such analysis was based on Bourdieu's theory that takes the means of communication (newspapers, letters and on-line means of communication) as an organized structured structure in which the structuring structure of societies is realized.

KEYWORDS: Migration. Means of Communication. Italy-BrazilJapan.

\section{Introdução}

A humanidade em sua breve história, sempre foi marcada pelo fenômeno das migrações, seja ela na antiguidade clássica com o a expansão dos grandes impérios tal como de "Alexandre, o Grande" ou mesmo pelo Império Romano, até o atual momento contemporâneo com populações inteiras migrando e imigrando pelas nações e pelos continentes nas mais diversas nuances deste fenômeno. A História, a Geografia, a Sociologia, a Antropologia, dentre outras ciências, tornaram-se "palco" de reflexões acerca desse movimento humano. Diante deste fato, é necessário pensar que as migrações em geral são marcadas por diversas influências, tais como as guerras, a fome, questões econômicas, dentre outras. 
No atual cenário, observa-se um grande número de migrações, principalmente advinda de regiões onde as guerras projetam um destino interminável. Síria, Afeganistão, Iraque, Líbano e a Palestina são exemplos de países assolados por guerras (internas ou externas) que cada vez mais se mostra insustentável a vida dentro de suas fronteiras. Uma das "soluções" encontrada por estes povos, se é que se pode referenciar desta forma, é a fuga para outras regiões que ofereçam certo grau de "segurança". Entretanto, seguir este caminho consiste em se aventurar colocando a sua vida, de seus familiares e amigos por inúmeros perigos durante as travessias. Infelizmente, a visão de caminhões e as embarcações lotadas de refugiados já se tornaram fato comum nos noticiários do mundo todo, bem como o fim trágico de alguns deles.

Uma imagem que chocou o mundo foi a foto de um dos refugiados, o menino sírio Alan Kurdi que morreu afogado em um naufrágio e foi encontrado na orla da praia de Bodrum na Turquia em setembro de 2015. Esta imagem revela um destino comum dos refugiados que migraram frente a guerra em seus países. De todo modo, é plausível apontar que o fenômeno da migração modifica completamente a identidade cultural de todos os envolvidos na migração. É também observável que o fenômeno da migração não está restrito a somente a movimentação de pessoas pela guerra. Diversos países possuem um histórico de migração com características que não se resumem diretamente a guerra, mas principalmente ligado a política e a economia, dentre outros fatores.

Neste sentido, o Brasil é um exemplo clássico. Ao analisar a sua história nacional, notadamente a fase escravocrata, o Brasil foi o destino de populações inteiras de todo o continente africano. Sobre este fenômeno é unânime a afirmação acerca das diversas dificuldades que os africanos sofreram desde a sua saída do continente africano para o Brasil até as suas relações políticas, econômicas, sociais e culturais na contemporaneidade. Dentre os diversos problemas, no início da fase escravocrata é notório citar que os membros de famílias, clãs, grupos e até mesmo cidades 
foram divididos e enviados para regiões diferentes para que não houvesse nenhum agrupamento e assim se rebelasse contra 0 sistema escravista que os diminuía em uma simples "força de trabalho". Não é novidade que este tipo de sistema tem por base a exclusão completa da cultura, da sociabilidade, da economia e da política dos subjugados, retirando destes os direitos humanos universais de liberdade, segurança, educação e até mesmo da vida.

O que restou à população africana foi a criação de novas relações familiares, sociais, culturais entre outras em um novo país diferente de suas regiões e países de origem. Com objetivo primordial da sua sobrevivência, os povos africanos foram obrigados a desenvolver novos hábitos alimentares, modos de vestir, aprender o português entre outros fatores que modificaram drasticamente suas culturas. Torna-se importante atentar que houve neste momento dois movimentos culturais africanos. Foi o primeiro momento o responsável pela mobilização da cultura africana a partir da memória dos primeiros migrantes e um segundo momento quando se adapta essa cultura ao seu novo contexto brasileiro. É fato, que este momento para a cultura brasileira é fundamental, principalmente pela nova conjuntura cultural da matriz africana. Entender a cultura como um processo em eterno movimento é essencial para ambas as culturas em questão. Para se pensar no papel da memória dos migrantes africanos, Henri Bergson (1999) nos auxilia afirmando que a memória é na verdade um prolongamento do passado no presente.

Para o presente artigo, o foco será dado entre três momentos históricos distintos e duas relações identitárias que se convergem em relações sociais semelhantes para a imigração e os meios de comunicação. Por mais diferentes que possa ser a imigração italiana no final do século XIX e japonesa no século XX, podemos estabelecer conexões de uso dos meios de comunicação distintos para organizar e estabelecer a identidade desses indivíduos. Além disso, pensar os meios de comunicação como estruturas estruturadas a partir de Bourdieu (1989) para reconhecer as estruturas estruturantes dessas sociedades. Essas configurações 
de deslocamento analisas utilizam os meios de comunicação para manter e permanecer "ligadas" de alguma forma com as suas áreas de origem. O desligamento provocado pela decisão e pelo processo de imigração e migração são, de certa forma, minimizados e reduzidos pelos meios de comunicação, sejam eles os jornais e cartas no século XIX ou as redes sociais, rádio ou comunicações on-line no século XX. Os meios de comunicação mudam em face a tecnologia, mas o objetivo de ligação com a terra natal permanece nos contextos estudados.

A cidade de São Carlos estava em um ponto privilegiado do estado de São Paulo (Brasil) na marcha cafeeira para o oeste, pois para a cafeicultura e suas técnicas de cultivo do período tinham relação significativa com a melhor fertilidade do solo (os solos recém desmatados tinham grande produtividade). Também, a idade mais nova do cafezal que geravam uma maior produtividade resultavam em lucros crescentes, além da chegada da ferrovia para a região (CANO, 1985, p. 301). Entre 1898 e 1902, dos 123.069 imigrantes distribuídos pelas fazendas de São Paulo, $40 \%$ concentraram-se nos municípios de Ribeirão Preto, São Simão, São Carlos, Araraquara e Jaú. Nesses municípios, as oportunidades de emprego eram maiores e a remuneração melhor, porque era permitido ao colono plantar produtos alimentares entre as fileiras do jovem cafezal. São Carlos é uma cidade desse vasto interior, formado pelo desenvolvimento da lavoura cafeeira, pelo forte movimento imigratório, principalmente italiano, e pelo crescimento da população no final do século XIX, assim se tornando um ótimo exemplo desse cenário. Esse é o panorama em que se encontra São Carlos: a chegada da ferrovia, grande produção de café, expansão econômica, a entrada maciça de imigrantes e, em decorrência, um grande aumento populacional, modificações do mercado de trabalho, transformações urbanas e ataque de doenças.

São Gotardo é uma cidade do Triângulo Mineiro que em razão do Programa de Assentamento do Alto Paranaíba - PADAP, que foi desenvolvido pelo Governo Militar na década de 1970 recebeu várias famílias de imigrantes japoneses e migrantes 
dessa etnia provenientes de outras regiões do Brasil. O objetivo do programa consistia em aproveitar o solo do Cerrado com tecnologia de ponta para a produção agrícola em larga escala. Para isso, o Governo Militar juntamente com a Cooperativa de Cotia - CAC trouxeram para a região por volta de 95 famílias de descendentes de japoneses para o desenvolvimento do programa (SASAKI, 2008). A escolha de descendentes de japoneses para o desenvolvimento do programa se deu em razão de acordos firmados entre o Brasil e o Japão para o aproveitamento do Cerrado. Santana (2015) afirma que o Brasil se comprometeu em ceder regiões para o correto aproveitamento do solo e o Japão colaborou com incentivos do ramo tecnológico e financeiro, mas que isso deveria ser colocado em prática por japoneses e ou descendentes de japoneses residentes no Brasil.

Desta forma, pretende-se com esse artigo mostrar como são as semelhanças desses dois processos migratórios nas estruturas estruturadas que consistem nos meios de comunicação para os envolvidos e sua construção como imigrante/migrante. Primeiro abordando São Carlos - SP no final do século XIX e depois São Gotardo - MG no final do século XX início do século XXI.

\section{São Carlos - SP no final do século XIX e a imigração italiana}

No que se refere a cultura nacional torna-se fundamental refletirmos sobre a migração europeia e consequências, principalmente na conjuntura da vida social brasileira. A migração europeia iniciada, notadamente nos séculos XIX e XX, que acabou por se tornar um grande fenômeno mundial, juntamente com os povos africanos, colaborou para a construção da identidade cultural brasileira. Em um contexto completamente diferente do período escravocrata brasileiro, a migração europeia se deu principalmente com a ênfase nacional da necessidade de mão de obra europeia junto a lavoras de café, que naquele momento representava o seu principal produto de exportação, ao lado da política de branqueamento da raça. 
O papel da propaganda com este intuito foi essencial para trazer para o país aqueles que se encontravam descontentes com a sua situação nos países de origem e também aqueles que viram no Brasil um país em crescimento. A propaganda brasileira na Europa fundamentou-se no conceito de um Brasil com um enorme potencial de crescimento dado a sua abundância de riqueza nas lavouras de café.

As propagandas e os subsídios desenvolveram papel fundamental no movimento migratório, especialmente na Itália, já que exaltavam as qualidades do Brasil, a imensidão de terras cultiváveis, o café conhecido como ouro verde e as possibilidades de conquistas econômicas - expondo um país como um paraíso terrestre. (CINTRA, 2010, p. 3).

Com esta "visão paradisíaca" do Brasil, vieram milhões de europeus, entre eles espanhóis, portugueses, alemães, poloneses e, sobretudo, italianos para o país. De acordo com Boris Fausto (1995), entre 1887 e 1930³, entraram no Brasil 3,8 milhões de europeus. O maior índice de entrada estaria entre os anos de 1887-1914 com a cifra de 2,74 milhões, isto representa $72 \%$ do total da imigração europeia. Esta numerosa entrada de imigrantes se deu notadamente para o trabalho nas lavouras cafeeiras. Com o início da Primeira Guerra Mundial (1914-1918), o número de imigrantes entrando no país foi reduzido, mas voltou a crescer a sua entrada no Brasil após o fim da guerra em 1918.

Os italianos formaram o maior grupo de imigrantes europeus no Brasil neste momento da história. Compete refletir que estes imigrantes sofreram muito para cruzar o Atlântico em direção ao Brasil. As viagens poderiam chegar a quarenta dias. Na grande maioria, estes imigrantes vinham de terceira classe nos navios, para amenizar os custos ou mesmo porque essa era a única forma para a imigração subsidiada. Com um grande número de pessoas,

3 A "Grande Crise de 1929" foi um dos principais fatores para o decréscimo de imigrantes europeus que entravam no Brasil. 
algumas inclusive doentes, os imigrantes italianos ficavam em espaços reduzidos por diversos períodos muitas das vezes com fome, com calor ou frio entre outras dificuldades.

A vinda dos imigrantes italianos ficou concentrada principalmente na região sudeste e sul do país. O porto de Santos em São Paulo, foi um dos primeiros pontos de chegada destes imigrantes. Fausto (1995) nos auxilia pensar no sentido de sua localização, principalmente neste primeiro momento de sua migração. De acordo com o historiador:

As regiões Centro-Sul, Sul e Leste foram as que receberam migrantes maciçamente. Um dado eloquente neste sentido: em $1920,93,4 \%$ da população estrangeira vivendo no Brasil estavam nestas regiões. O Estado de São Paulo se destacou no conjunto, concentrando sozinho a maioria de todos os residentes estrangeiros no país $(52,4 \%)$. [...] Considerando-se o período $1887-1930$, os italianos formam o grupo mais numeroso, com $35,5 \%$ do total, vindo a seguir pelos portugueses $(29 \%)$ e os espanhóis $(14,6 \%)$. (FAUSTO, 1995, p.154).

É importante destacar também que o governo de São Paulo arcava com as despesas de viagem e assentamento destes imigrantes, pelo ao menos neste primeiro momento. De fato, inicialmente o governo subsidiava as passagens e seu assentamento, e posteriormente os contribuintes eram os fazendeiros, os principais interessados nesta nova mão de obra.

A partir de sua chegada é iniciado um processo de mudança em todo o contexto cultural, social, econômico destes imigrantes italianos. Desde a sua instalação nas fazendas até seu trabalho diário nas lavouras, o país se mostrou que não era um "paraíso", como era tanto enfatizado pelas propagandas, mas sim um local com diversas dificuldades. Com muito trabalho, estes imigrantes vão conquistar o seu espaço dentro da sociedade brasileira e se tornarem um importante grupo dentro de todo o cenário.

Costa (1999) descreve como a narrativa das condições de trabalho e vida no Brasil eram ilusórias advindas dos governos, 
das companhias de navegação, principalmente a Companhia Vergueiro e Cia., e dos agenciadores:

O mau recrutamento dos colonos pelos agentes brasileiros e pelas municipalidades europeias tornou-se proverbial. Os primeiros visavam apenas ao maior número e as administrações locais procuravam livrar-se, muitas vezes, de munícipes indesejáveis. Para induzir os indivíduos a emigrarem, os agenciadores faziamIhes promessas ilusórias, acenando com visões paradisíacas, prometendo todos os sucessos e facilidades aos emigrantes. (COSTA, 1999, p. 221-222).

Contudo, esses não eram os únicos responsáveis, os jornais do período também faziam parte desse processo e as próprias redes de comunicação entre os familiares e amigos dos imigrantes. Uma das formas comuns de estabelecer contatos era por meio de cartas ou pelos jornais do período. Emilio Franzina (1994) compilou diversas cartas de migrantes venetos e friulanos (províncias italianas) no período entre 1876-1902 em seu livro Merica! Merica!. Dentre estas cartas destaca-se a de Giovanni Polese que dá direções de como o sogro deveria fazer a vinda para São Carlos - Brasil se assim fosse de seu julgamento, para essa decisão no decorrer da carta ele dá diversas informações de como é o pagamento pelo trabalho realizado no Brasil, se tivesse uma cozinheira que o pagamento seria melhor, que teria a necessidade de trazer uma irmã para isso, que a viagem era difícil e poderiam encontrar ladrões durante o percurso com a desculpa de trocar o dinheiro, roubavam as famílias, tendo ele presenciado uma dessas situações (FRANZINA, 1994, p. 132-133). As redes de informações sobre como eram as condições de trabalho e a vida cotidiana no Brasil são uma grande fonte de informações para os imigrantes, é por meio delas que se estabelecem e se organizam as imigrações em muitos momentos. Os jornais também divulgavam as cartas que se encontravam nas suas redações para a distribuição. Abaixo um exemplo de como era essa divulgação em São Carlos pelo jornal Diário de São Carlos de 11 de janeiro de 1890. 


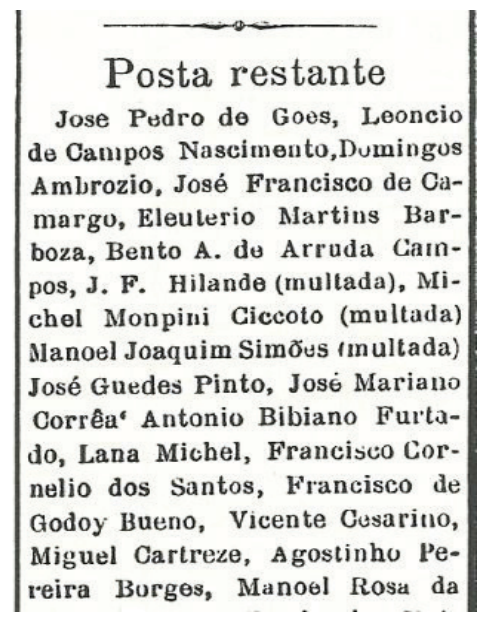
Silva, Vicenzo Zamborda, Epi-
macho Nery de Carvalho, Joa-
quim Alves Moreira, Francisco
Bueno Rosa, Antonio Guimarães,
Paulino de Arruda Campos, Juão
Antonio de Camargo Alves, José
de Salles Pimenta, Cazali Bevia-
nino, João Alves Ferreira, revd.
João F. da Gama, Rita Leocadia
da Silva, Luiz Hampperto, Joa-
quim Leite de Mesquita.
Regrstrabas
José Contreiras Martins, Tur-
chetto Pasqualo, Antouio Dias
Ferraz, Manzini Antonio, Manoul
Luiz da Matta.
E

Diário de São Carlos, São Carlos, 11 de janeiro de 1890

O número de cartas na redação do jornal Diário de São Carlos variava muito, mas cabe ressaltar que algumas dessas estão salientadas como "multada", um alerta sobre o que era a correspondência. Outros jornais prestavam o mesmo serviço em outros anos para São Carlos, assim como outros periódicos em outras cidades tinham o mesmo comportamento, eram pontos de recebimento e informações para a população.

Os jornais eram verdadeiras pontes de ligação e conexão entre o país de origem e o país de recebimento. As notícias vinculadas pelos jornais no final do século XIX eram relatos do cotidiano da sociedade, um pouco diferente e mais distante da configuração dos jornais atualmente. Alguns artigos faziam referência a acontecimentos na Itália numa relação de manutenção com o cotidiano do país, como por exemplo, os desastres naturais publicados pelos jornais em São Carlos. 


\section{Terremotos na Calabria. -}

Refere telegramina de Messina que 0 aspecto da Calabria $\dot{\theta}$ deso. lador. Toda a rogiano foi derasta: de pelo terremoto: $0 s^{\circ}$ tremores de terra destruiram S. Procopio.

Houve 60 mortos e ficaram debaixo das ruinas 48 possoas. 0 resto dos habitantés pódo escapar da catastrophę, fugíndo para as cemnos.

O Popular, São Carlos, 25 de novembro de 1894.

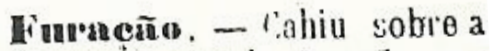
Sicilia uuna gratede luraçăo que derrubou casas, produzimb morles e terinembs e occaicnando navfragios.

Ordem e Progresso, São Carlos, 8 de março de 1895.

Outros artigos se referem a ações do governo italiano como os três exemplos a seguir.

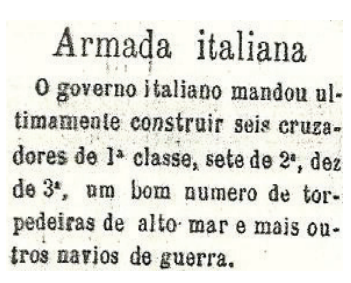

Diário de São Carlos,

São Carlos,

2 de março de 1890

\section{Que bilontras!}

Ein Palermo a justiça desco. bríl que diversos altos funccio. narius da policia, inspectores, delegados e o proprio chefe de po. licia havians formado entre si uma associação para extorquir dinheiro aos delinquentes. Tudos os socios foram presos e o chefe de policia foi demettido.

Diário de São Carlos, São Carlos, 22 de maio de 1890
0 rei da Italia acceiton a presidencia honoraria da commissão encarregada de celebrar o quarto centenario da descoberta da America. 
Os jornais, como forma de comunicação, são tomados para Bourdieu (1989) como estruturas estruturadas, isto é, externas aos agentes da ação que por meio delas é possível entender e analisar as construções sociais. Os jornais e as cartas desempenham papel fundamental para a compreensão da identidade construída no período. Percebe-se que a preocupação com as narrativas de fatos ocorridos na Itália criava e mantinha o pertencimento dos imigrantes. Mesmo porque muitos imigrantes eram negligenciados e depreciados pela população em geral, assim como eram integrados e aceitos pela sociedade brasileira, mantinham o vínculo de inclusão com a Itália. Primeiro, porque necessitavam ser identificados com uma nação, ainda que para muitos era "novidade" e precisavam ter mais conhecimento dela. Lembra-se que a Unificação Italiana ocorrida em 20 de setembro de 1870 era muito recente e pouco internalizada. Os imigrantes quando aqui chegaram se autorreconheciam como sicilianos, calabreses, genoveses, mas os locais os identificavam como italianos. A comunicação dada era responsável por parte da estruturação da identidade desses imigrantes italianos em São Carlos - SP.

Em um artigo do jornal Ordem e Progresso exatamente com o título de Calábria, reivindicava melhorias para a região oposta à região central que se localizava a Catedral assinado por um pseudônimo, Asinus ${ }^{4}$. O próprio título evidencia a regionalidade, que era superior ao entendimento de nação que estava se construindo quando migraram, percebe-se claramente aqui o papel de estrutura estruturada que desenvolvida pelo jornal para estabelecer a estrutura estruturante de sociedade. Segundo o artigo, a região não possuía muitos "eleitores" 5 e, portanto, tida pelo poder local como "só habitado por nullidades". A situação do local era de falta de policiamento, ruas esburacadas, sem

4 Não foi encontrada nenhuma evidência que levasse a saber quem era de fato o articulista, mas pelo teor das reivindicações e a descrição dos fatos, ele provavelmente habitava essa região e pela predominância da nacionalidade italiana nela, um membro da colônia.

5 Lembra-se que os estrangeiros não votavam. 
iluminação, e haviam colocado um poste, mas sem lâmpada que durante a noite era um obstáculo difícil de ser identificado. A região necessitava de melhoramentos, mesmo que não houvesse "eleitores", existia a necessidade de melhorais porque lá eram gerados muitos impostos, pois o comércio estava também localizado naquela região. Segundo o artigo, os "melhoramentos necessários, esses ficam no tinteiro, ao menos quanto à parte da cidade denominada Calábria". Tal artigo afirmava o descaso da intendência nessa área, que viria a ser muito afetada pelas epidemias de febre amarela no ano de 1896. De fato, o lixo acumulado, o descaso e as doenças estão intimamente ligados, principalmente para a população do período.

\section{A UALABRIA ENS CARLOS QUALIFICACZ̃o}

Dicidudamenta é accessarıo que o povo despente d'essa lethargia que o toına uma verdadeira massa inerte a que dous ou tres (mais esperlos) meven a sua von. lide I

Assim não deve ser: o pcroo o que deve dizer aus seus procura. dores o que quer quis elles taçam e, llav, os procuratores determinarem o que deve str feitis!

Quc. erit o povo que se concenIre toda a boa vonlate da intendencia cm um ponto determinato la cidade, destalorisando por esta forina, o resto?

De certo que nao!

Mas entao porique motivo assim procede a no sa in:enden cia?

P'orque, sendu o numer., de eleitores bastunle limitido e este mesmo numero limitado, tendo sua residencia nos arredores da matriz, certamente que hio de i uchar a sardinha para seu lado !
Ora, do lato ita cilade denominado "íalabritn, contados sio os que tem o titulo de ele tores e purtanto a intendencia julga (e com razão) que nåo deve prestar attençào para este ponto de S. Carlos só habitado por nullidades I E nâo será este o termo proprio?

O homer qne nio é eleitor nåo ế e nảo deve ser consiılerado um cidadão e desde que nảo é cidadäo, Á nada, ou nullidade I

Eistretanto toilos nós concor. rencs con o nosso auxilio (inpostos). para que mclloramenios sejam feitos; mas, si ao mesmo tempo yue damos o nos in dinheıro, Viramos ás costas ìnuelles que ficam encarregados de distribuil-os em melhoramentos, es claro que esse dinheiro será sem pre empregalo mal !

Pegoi em um grosso capitil e collocai o na máo de um inexpe. riente e ide-vos passear: quando tornardes, a saber o que foi feito d'esse dinheiro, tereis $\mathrm{em}$ resposta que não sabem o que foi feito d'elle I

E' portanto, muitı justo o motivo porijue digo aos residentes na "Calabıia": alerta, aleıta I!

Os impo.tos sâo sempre pagos e os melhoramentos ná apparecem; crmp e que vos qualifiqueis. e yue i'e,oors de vos 'ornar. des eleitores, unidos como u:n só homem, Iroteis de eleger alguem que seja le vossa confiança para zelar pelos vossos inu resses.

Mais uma : exista na parte da ridade denominada Calabria, Ialvez mainr força de commercio que no parte de cima ; entretanto qual os o policiamento leito n'esta parte deslazorecida?

Iniminuto, em extraordinaís. o numero de pracas encarregatas de zelar peli ordem em uina cidale tio prospera, como S. Carloz; ainda d'esse diminuto numero, i preciso que uma parte tique sempro na tarleia, faça-se a calculo e hảo de vêr que o policiamento è in ullicientissimo!

Convindo ainda notar que es:e numero pequenissimo fica, provavelmente, guarnecendo a uci. dade privilcyialis"... e o que fica para a desimparada Calaliria?

Estou cesto, que niesta paite les, larlos, nao se da sempre crimesile toda especie, devilo á indole orileira do povo que n'ella residle.

Nada, nada pela Calabria. porque?

Porque, romo já dizem, seus habitantes tem dormido até hoje... mas lespertarão em breve pois a qualificáça está ahi e nîo se poilerdo queixar si quizerell continuar dermindo

portanto à qualificaça, porque i vós não defenderiles os rossos interesses, quem os defendera? Asinuj.

Ordem e Progresso, São Carlos, 27 de abril de 1895. 
Percebe-se claramente que a denominação de Calábria, de apenas uma região para uma nação, os imigrantes italianos ainda estavam em processo de construção da identidade. Outra relação é que a aglutinação pela defesa e melhoria de uma parte da cidade sendo construída por meio do artigo do jornal. É o articulista que sem qualquer identificação alerta a população para a mobilização contra a intendência. Todos esses aspectos são estruturas estruturadas da condição do imigrante italiano no final do século XIX no interior do Estado de São Paulo.

\section{São Gotardo - MG no final do século XX início do século XXI e a imigração japonesa}

Outro momento da história da migração brasileira é a imigração asiática, que se iniciou a partir de 1908 com os japoneses. Tal como os italianos que migraram para o Brasil devido as propagandas de um Brasil com variadas riquezas, o Japão também foi plano da propaganda política brasileira com objetivando uma outra formação de mão de obra nas lavouras de café paulistas. A imagem a seguir demonstra este tipo de propaganda no Japão.

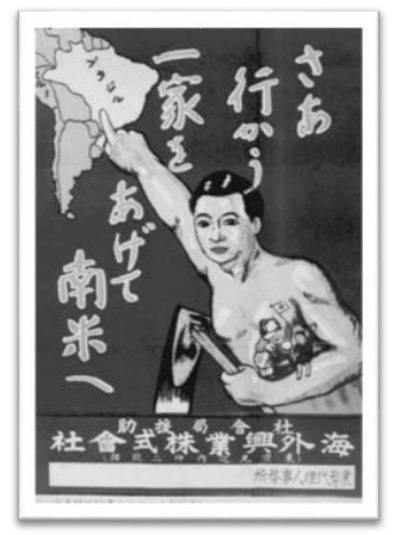

Cartaz de incentivo a migração japonesa para o Brasil ${ }^{6}$

6 Disponível em: <https://pt.wikipedia.org/wiki/lmigra\%C3\%A7\%C3\%A3o japonesa_no_Brasil\#/media/File:Affiche_\%C3\%A9migration_JP_au_BRd\%C3\%Ā̄b._XXe_s..jpg>. Acesso em: 5 jul. 2016. 
O cartaz acima explicita a propaganda que impulsionou os japoneses nesta empreitada de migrar para o Brasil. Ao observar o cartaz, nota-se a preferência por trabalhadores rurais (pelo personagem carregar uma enxada), o que de fato foi verificado com a chegada dos imigrantes no Brasil em 1908. Entretanto, entre os imigrantes estavam também pedreiros, pescadores, carpinteiros, ferreiros e outros interessados.

Tomemos por nota que o interesse de migração não era somente pelo governo brasileiro mas também pelo governo japonês. A chamada "Era Meiji" (1868-1912) marcou o Japão pela profunda reforma política, social e principalmente industrial do país. Durante este período o desenvolvimento do Japão foi levado a diversos setores da sociedade, inclusive o espaço rural com uma intensa Reforma Agraria. O desenvolvimento desta última revelou um grande excedente populacional, o que levou o governo imperial japonês a incentivar também a política migratória.

Outra discussão que merece destaque é que a viagem por ser mais longa era naquele momento uma das mais penosas. Uma média de 50 dias de viagem e acomodações no navio na terceira classe (tal como os italianos) eram algumas das dificuldades que os imigrantes se deparavam na sua trajetória para chegar ao Brasil. Durante as viagens estes migrantes não se resumiam a somente um grupo étnico japonês, mas diversos grupos com pessoas de todas as partes do Japão com uma série de dialetos, culturas e modos de viver diferentes se encontravam em um único espaço onde a convivência era obrigada por 50 dias. Da mesma forma que os italianos, que pertenciam a grupos étnicos e identidades das mais variadas, muitos desses grupos se descobriam "italianos" ou "japoneses" no Brasil em contraponto ou confronto étnico.

Havia um contraste nítido nos dialetos, no comportamento entre os que saíram das províncias "atrasadas" e "pobres", de forte tradição rural como Okinawa e Kagoshima, e os das províncias mais "nobres", da ilha de Honshu, onde se localizam Tóquio, Kyoto, Osaka, cosmopolitas e engajadas no processo de modernização 
industrial. Para a grande maioria, era a primeira vez que saíam da terra onde haviam nascido e, por tanto, o primeiro contato direto com japoneses de outras partes do país. (SAKURAI, 2008, p. 124).

Ao chegar ao Brasil, os desafios destes imigrantes aumentam consideravelmente, principalmente pelas inúmeras diferenças da língua portuguesa, das vestimentas, da alimentação entre outras em relação a sua cultura de origem e as diversas identidades japonesas presentes. Adaptar-se ao novo meio não é somente uma escolha, mas uma necessidade para sua sobrevivência.

A migração teve um caráter de promoção econômica desde o final do século XIX até o presente momento, apesar de não ser esse o objetivo do governo brasileiro. Franzina discute sobre esse "desvio" e vontade explicita dos migrantes de se tornarem proprietários de terra ou retornarem a Itália no final do século XIX.

mais facilmente realizar o sonho de ser proprietário de terras e emigrar que mandavam informações dos centros urbanos da parte sul do continente ou, mais frequentemente, de lugares voltados à colonização agrícola, mas em sua forma mais "alterada" foi a do trabalho assalariado e semi servil da plantação em São Paulo ou Espírito Santo. (FRANZINA, 1994, p. 44, livre tradução7).

Ao pensar sobre a história da migração do Brasil é verdadeiro afirmar que possuímos dois momentos deste fenômeno. Num primeiro momento do fenômeno migrante o Brasil é um lugar de chegada de milhares de pessoas, inicialmente com a população africana (aproximadamente dos séculos XV até XIX) e depois as populações europeias e asiáticas (XIX e XX). Este primeiro momento foi marcado por um intenso número de pessoas chegando ao país. Em um segundo momento, os brasileiros

7 [...] piú facile coronare il sogno dell'impadronimento della terra ed emigranti che mandano invece notizie dai centri urbani del subcontinente oppure, piú spesso, dai luoghi votati sí alla colonizzazione agricola, ma nella sua forma piú "spuria" che fu quella del lavoro salariato e semiserville di piantagione in San Paolo o in Espirito Santo. (FRANZINA, 1999, p. 44). 
passam a migrar para outros países, principalmente a partir da década de 1980. Muitos destes migrantes são descendentes dos imigrantes europeus e asiáticos e veem nos países de origem de seus antepassados a chance para alcançar seus objetivos, sejam eles culturais, financeiros, sociais etc.

A migração de brasileiros é muito menor que o fenômeno migrante de seus antepassados. Entretanto, essa nova migração nos evidencia mudanças substanciais na cultura dos povos envolvidos com a mesma. O chamado Movimento Dekassegui ${ }^{8}$, que resumidamente, é o fenômeno migrante de nipo-brasileiros para o Japão, nos auxilia a fazer algumas reflexões de como a cultura dos envolvidos modificou-se consideravelmente após a migração. Ao entrevistar descendentes nikkeis de São Gotardo, no interior de Minas Gerais, foi observado como a vida social destes migrantes mudara após sua ida para o Japão e sua volta depois de algum tempo ao Brasil ${ }^{9}$.

A maioria das famílias nikkeis em São Gotardo - MG após 1970 era proveniente do estado do Paraná, sendo que algumas eram do estado de São Paulo, e outras inclusive diretamente do Japão. Com o desenvolvimento do Programa de Assentamento do Alto Paranaíba - PADAP, muitas das famílias nikkeis obtiveram sucesso na produção agrícola e se tornaram grandes empresas deste setor com reconhecimento local, nacional e algumas, até mesmo, internacional. Luiz Sasaki (2008) afirma que os primeiros

8 O termo "dekassegui" em japonês é formado por dois ideogramas (kanji), Deru (sair) e Kassegu (trabalhar para ganhar a vida), sendo aplicado a qualquer pessoa que deixa sua terra natal para trabalhar, temporariamente, em outra região. Originalmente, este termo era aplicado aos trabalhadores sazonais, principalmente do norte do Japão, que no inverno procuravam trabalho mais ao sul. Hoje, no Japão, este termo é aplicado aos trabalhadores estrangeiros temporários que estão naquele país com o intuito de ganhar dinheiro (exclui os expatriados - trabalhadores de firmas estrangeiras) (BELTRÃO; SUGAHARA, 2006).

9 Muitas destas entrevistas foram realizadas com intuito de fomentar as reflexões de modo qualitativo no trabalho dissertativo sobre a presença nikkei em São Gotardo. Usaremos alguns trechos destas entrevistas para pensarmos o movimento da cultura entre os Dekasseguis. 
quatro anos foram de extremo trabalho e sem muitos resultados. Após esta fase o programa operou com êxito ${ }^{10}$.

É fato que nem todas as famílias que participaram do programa desfrutaram o esperado sucesso junto ao programa. Muitas famílias tiveram fracassos em sua produção agrícola fazendo com que os mesmos procurassem outra forma de sobrevivência. A ida para o país dos seus antepassados se tornou a resposta para muitos destes nikkeis. Com a crise econômica que o Brasil viveu principalmente na década de 1980, os nikkeis viram no Japão, que naquele momento vivia seu ápice de crescimento econômico, a chance de se enriquecer rapidamente e investir em outros negócios no Brasil. Elisa Sasaki discute neste sentido.

As duas últimas décadas do século XX, o contingente do Brasil, país até então visto como receptor de imigrantes, começou a se dirigir ao estrangeiro. Dentre os diversos destinos, o Japão é um dos que têm recebido um expressivo contingente de brasileiros que foram para trabalhar em ocupações de baixa qualificação, especialmente no setor manufatureiro. Com a crise econômica no Brasil e a concomitante prosperidade no Japão, ir para o "país dos seus ancestrais" passou a ser considerado uma alternativa diante da crise econômica que marcou a situação brasileira nos anos 1980. Não são os pobres que emigram ao exterior, mas uma classe média que tem tentado manter ou elevar seu padrão de vida. Trata-se de filhos e netos de imigrantes japoneses que no início do século XX vieram ao Brasil e que estão indo agora para o Japão com as mesmas intenções de seus ancestrais: trabalhar temporariamente para retornar enriquecido para o seu país de origem. (SASAKI, 2006, p. 99).

Um ponto importante que a autora aborda, é que estes migrantes ou dekasseguis não são da classe C ou da classe

10 Acreditamos que seja necessário abordar que o cenário atual da cidade (seja ele no setor social, cultural, econômico e político) está grandemente voltado para o agronegócio, que majoritariamente foi implementado pelo sucesso do programa. 
mais humilde, eles são em maioria da classe média brasileira. No caso dos nikkeis de São Gotardo, essa estatística não foge a regra. Durante as pesquisas com os migrantes, todos se referiram como membros da classe média, possuindo bens, tais como terras (provavelmente proveniente do PADAP), casas, comércios, carros entre outros.

Estima-se que até 2008, o Japão contava com 318 mil nipobrasileiros, colocando o grupo brasileiro como o terceiro maior grupo de imigrantes dentro da nação nipônica (SAKURAI, 2008). Em grande parte, os dekasseguis são contratados para trabalhar como mão de obra em indústrias (principalmente com maquinário pesado tais como a indústria de construção naval, automobilística e aeronáutica) ou mesmo em serviços com baixa qualidade de todos os tipos. O que torna incompatível esses tipos de emprego é que os nipo-brasileiros que vão para o Japão são em sua grande parte detentores de formação universitária e encabeçam empregos rejeitados pelos japoneses (BELTRÃO; SUGAHARA, 2006).

A questão acerca destes tipos de empregos onde os dekasseguis são contratados, fomenta ainda mais a discussão sobre o preconceito diário dos japoneses para com os nikkeis brasileiros. Longe de afirmar que estes nikkeis estariam imunes a qualquer tipo de ataque ou pratica preconceituosa no Brasil, até porque a própria história nacional confirma infelizmente estas práticas. O que se pode afirmar que atualmente no Brasil esse preconceito é enormemente mais velado.

No caso especifico dos nikkeis de São Gotardo, a questão da diferença étnica possui uma tônica bem diferente. Em razão do sucesso obtido na agricultura, os nikkeis são vistos na cidade como "portadores do sucesso", seja ele social, cultural e principalmente econômico. A discussão deste tema torna-se fundamental para entender o preconceito enfrentado por estes nikkeis ao chegarem ao Japão. Bourdieu (1989), em suas reflexões, afirma que este tipo de valorização é comum nas sociedades e funciona como forma de estruturação da mesma por meio do que ele conceitua como "capital simbólico". Em uma explicação simplista, o capital 
simbólico seria a concessão de um status ou poder de alguém dentro do processo atribuído por uma dada sociedade no capital global pelas relações de capital econômico e capital cultural (BOURDIEU, 2008). No caso dos nikkeis de São Gotardo, a população geral não descendente atribuiu aos nikkeis o poder de serem "pessoas ricas ou portadoras com grande sucesso econômico" dentro da sociedade são gotardense. Esta atribuição seria para Bourdieu (1989) um tipo de relação entre o capital econômico e o capital cultural que se torna um dos fatores primordiais para o seu status no espaço social. O espaço social são gotardense se encontra então em um domínio nikkei onde dois capitais são atribuídos aos descendentes de japoneses e ao mesmo tempo são recebidos com louvor pelos nikkeis que ganham com estes capitais dentro de São Gotardo.

É importante afirmar que os nikkeis ao chegarem para o desenvolvimento do programa (PADAP) não se posicionaram acima dos locais em um primeiro momento, mas isso foi se desenvolvimento principalmente pelos não descendentes a partir do sucesso econômico obtido pelos nikkeis.

De acordo com Bourdieu (1989, p. 145),

O capital simbólico - outro nome da distinção - não é outra coisa senão o capital, qualquer que se seja a sua espécie, quando percebido por um agente dotado de categorias de percepção resultantes da incorporação da estrutura da sua distribuição, quer dizer quando conhecido e reconhecido como algo de obvio.

Quando estes nikkeis chegaram ao Japão, estes se depararam com um ambiente social que não mais existia aquele capital simbólico que os colocava em um lugar especial dentro da sociedade. No país de seus antepassados, os nipobrasileiros são vistos muitas das vezes como descendentes daqueles que desertaram do Japão antes da Segunda Guerra Mundial, abandonando o país quando mais ele precisava de seus "filhos". É crucial lembrar que o Japão era uma das potencias do Eixo e sofreu graves consequências da guerra tais como a 
desestruturação da economia, política, saúde e ainda suportou o bombardeio das primeiras armas nucleares em Hiroshima e Nagasaki no final da guerra. Para a história japonesa, este é um dos momentos mais dramáticos do país.

Quando os avós comentam que diversos japoneses deixaram o país frente a iminente guerra e não suportaram este dramático momento de reconstrução nacional, induz que os "desertores" feriram o "orgulho nacional". Diversos autores que estudam a temática migrante dos brasileiros no Japão tratam deste tipo de abordagem. O que torna ainda mais ainda importante esta reflexão é como este tipo de pensamento foi repassado entre as gerações japonesas e de fato foram colocadas em prática com a chegada em massa dos nipo-brasileiros a partir da década de 1980.

De acordo com os entrevistados este é um dos problemas que acompanham os nikkeis brasileiros da sua chegada até a volta ao Brasil. Um dos entrevistados afirmou que em algumas das vezes ao conversar no metrô em português no telefone ou com algum amigo brasileiro, os japoneses ao redor se levantavam e iam para outro lugar. "Este tipo de reação deles [dos japoneses] é normal! Com o tempo você vai acostumando". (Paulo Hinamoto, empresário, 34 anos, 1 de março de 2014) $)^{11}$.

Os dekasseguis discorreram com veemência outra dificuldade que para os mesmos era ainda mais grave, a língua. Por não ter tido mais contato com a língua, estes brasileiros chegam ao Japão tendo conhecimento de poucas palavras essenciais como pedir comida, água, ajuda e com o passar do tempo e muita força de vontade eles aprendem o básico do japonês. De acordo com os entrevistados, existem nas comunidades brasileiras ${ }^{12}$ escolas de japonês que ensinam a língua, cultura e geografia do Japão. Essas

11 Todos os entrevistados tiveram seus nomes alterados para preservar suas identidades.

12 As comunidades brasileiras são grupos de descendentes de japoneses que convivem de modo virtual (por meio de redes sociais de grupos de residentes no Japão) ou presencial em bairros, distritos e até mesmo microrregiões onde os integrantes possuem o objetivo de cooperação nos diversos contextos da sociedade japonesa e sua adaptação. 
escolas tem um papel fundamental na orientação dos nikkeis brasileiros neste primeiro momento de suas vidas no Japão.

Outro entrevistado, o senhor Ukio Tanaka, afirmou que o conhecimento da língua é fundamental para a inserção dos brasileiros na sociedade japonesa em todos os sentidos. "Nos primeiros meses eu penei, sofri! Depois que eu aprendi a falar o japonês, o mundo se abriu pra mim! Falo bem e isto me ajudou muito!" (Ukio Tanaka, aposentado, 70 anos, 1 de março de 2014).

As comunidades possuem um papel importantíssimo não somente na questão da educação, mas, sobretudo no auxílio à moradia, a socialização e até aos empregos para os nikkeis, que muitas das vezes chegam ao Japão e não conseguem empregos além de contratos temporários. Estas comunidades funcionam auxiliando o migrante em toda a sua inserção e sociabilidade dentro do Japão.

Por outro lado, estas comunidades contribuem no isolamento dos nikkeis brasileiros que acabam por socializar somente entre os mesmos, o que acaba dificultando ainda mais a sociabilidade com a sociedade japonesa (SANTANA, 2015). Muitos nikkeis brasileiros criam seus círculos de amizade dentro das comunidades, o que pode criar empecilhos inclusive no uso da língua japonesa, já que entre os nikkeis brasileiros o idioma na maioria das vezes é o português.

Se por um lado o capital social é o responsável pela coesão dos grupos comunitários, por outro lado o mesmo é também responsável por limitar a sociabilidade dos nikkeis com outros indivíduos que não fazem parte da comunidade. Robert Putnam (2002) discorre sobre este tipo de fenômeno que é natural dentro das comunidades imigrantes. O capital social amplia os laços de amizade e ajuda dentro da comunidade, entretanto o restringe a sociedade em geral que o mesmo vive. A identidade compartilhada dentro da comunidade ou mesmo com os familiares e amigos no Brasil não é a mesma identidade da sociedade japonesa e estas diferenças se não forem bem administradas pelo imigrante pode se tornar um grande problema para o nikkei.

No que se refere à identidade dos nikkeis, torna-se 
fundamental pensar na cultura mobilizada pelos mesmos. É fato que a cultura está sempre em movimento, se modificando a cada instante e no caso nikkei esta dinâmica cultural se torna ainda mais evidente após a migração para o Japão, onde se inicia todo um processo de transformação da cultura destes brasileiros. Seja ela pela comida, pelo clima, pelo trabalho, pela família entre outros fatores, a cultura dos nikkeis brasileiros ao adaptar-se a cultura japonesa exemplifica este movimento interminável e universal que é próprio da cultura.

Ir a algum show musical japonês, ao teatro, aos bares para confraternização ou mesmo sair com os amigos para fazer compras nos shoppings são algumas mudanças que os nikkeis brasileiros retratam sobre seu dia a dia no Japão e que de certa forma estas ações colaboram para pensarmos em como a sua cultura vai se modificando. A própria relação da facilidade compras no Japão é um dos primeiros tópicos citados pelos entrevistados. "Com dois dias de trabalho compro um celular ou um notebook que eu quero!" (Carlos Tanaka, 28 anos, empresário, 1 de março de 2014). Isso foi dito por vários entrevistados de diferentes maneiras. A facilidade com que os mesmos possuem em adquirir algo modifica o pensamento de aquisição trazido do Brasil, onde a aquisição não é tão fácil para essa classe social que imigrou. É importante atentar que estes tipos de eletrônicos vão colaborar na comunicação entre os mesmos e o Brasil de seus familiares, estabelecendo uma ponte virtual entre o Brasil e o Japão.

Com a evolução tecnológica, principalmente dos últimos dez anos, estes dekassegui passaram a ter um contato ainda maior com seus familiares e amigos no Brasil, consolidando uma nova fase cultural da migração mundial. A tecnologia proporciona para estes migrantes um contato continuo com seus países de origem, criando uma cultura para estes migrantes com elementos tanto de sua terra natal como do lugar para onde migrou.

No caso dos nipo-brasileiros passaram a exemplificar este eixo da migração onde os mesmos possuem um contato com a cultura brasileira por meio de seus familiares e amigos, e ao mesmo tempo com a cultura local japonesa do seu dia a dia. 
Canclini (2007) define o conceito de "interculturalidade", que se torna bastante presente e interessante quando pensamos nos migrantes.

Os meios audiovisuais, o correio eletrônico e as redes familiares ou de amigos tornaram incessantes os contatos intercontinentais que no passado levavam semanas ou meses. Não é a mesma coisa o desembarque de um navio e uma aterrisagem, nem a viagem física e a navegação eletrônica. A interculturalidade hoje se produz mais por meio de comunicações midiáticas que por movimentos migratórios. (CANCLINI, 2007, p. 73).

Conversar com os familiares no Brasil por telefone enquanto está fazendo diversas tarefas no Japão se tornou uma rotina para os dekasseguis após o advento da tecnologia. "Eu conversava quase todos os dias com meus pais, enquanto eu estava saindo da fábrica. Só não conversava mais porque eu ligava para eles as sete da manhã do Brasil, né" (Paulo Hinamoto, empresário, 34 anos, 1 de março de 2014). Então se pode perceber um duplo movimento de apoio das tecnologias para a migração, o primeiro é estabelecer o contato com os familiares e os indivíduos de sua convivência, aplacando a "dor" do deslocamento e da separação do grupo de convivência. O segundo momento é a manutenção da cultura e da identidade cultural do país de origem. Entre os imigrantes italianos do final do século XIX, nos relatos de retorno é comum encontrarmos a narrativa que não reconheciam a Itália que haviam deixado, exatamente pelas modificações inerentes a cultura. Como os meios de comunicação não eram on-line, não havia o "tempo real", os indivíduos que deixavam a sua terra natal por longos períodos e depois retornavam não se reconheciam mais como pertencentes àquela cultura da mesma forma que aqueles que dali não saíram.

A vida social destes migrantes para o Japão é dupla, por um lado eles possuem um contato virtual com o Brasil em suas várias facetas seja ela no trabalho, na casa e no lazer de seus familiares e amigos e por outro lado convivem diariamente na sociedade 
japonesa com os mesmos contextos acima. A cultura destes nikkeis brasileiros poderia ser definida como uma cultura "híbrida" como diria Canclini (2007). No momento das entrevistas, tornavase claro este eixo que a cultura dos nikkeis tomava ao voltar do Japão. Um exemplo deste hibridismo cultural é a linguagem dos decasséguis no século XX. A mistura de palavras em japonês com o português se tornara um fato comum principalmente entre os decasséguis. No caso de São Gotardo observa-se o exemplo deste movimento cultural, que durante uma de nossas entrevistas, ao esperar o entrevistado nikkei pegar uma garrafa de água, notamos que a mãe do mesmo, uma senhora japonesa com idade aproximada de 80 anos, nascida no Japão e residente no Brasil a mais de 60 anos, ainda ouvia um telejornal japonês da região onde viveu quando criança. A senhora conversou em português (sobre onde estava a garrafa) com o filho e comentou em japonês algo em relação à reportagem que estava passando na televisão. Por curiosidade perguntamos há quanto tempo ela acompanhava as notícias japonesas, ele afirmou que desde quando nasceu viu os pais "conectados" ao Japão.

No caso decasségui, este aspecto cultural se evidencia ainda mais, os entrevistados afirmam que no Japão a alternância de idiomas é um fator básico entre os descendentes de japoneses do final do século $X X$ e no século $X X I$ e isso reflete culturalmente sobre suas identidades. Torna-se indispensável apontar que estes migrantes estão envoltos em um processo onde existe uma negociação interrupta e clara que suas identidades perpassam ${ }^{13}$. Referenciar algo ou alguém em português ou japonês evidencia

13 O que a autora chama a atenção para os problemas de readaptação, de fato foi observado com um dos entrevistados. Durante as entrevistas, sente-se um certo tipo de "falta de território", onde ambos os lugares (Japão e Brasil) não são vistos como lugares permanentes dada a sua insatisfação. Acreditamos que esta discussão não seja somente deste grupo até porque a grande parte dos migrantes "contracenam" com inúmeros contextos (tais como da família, do trabalho, de suas aquisições, da saúde entre outros) de cada país, região ou lugar, escolhendo o melhor de cada um e os reservando em seus pensamentos. 
esta negociação entre os decasséguis. Devemos pensar também que todo o universo cultural destes migrantes está passando por transformações complexas que os mesmos tentam acompanhar criando novas interfaces desta cultura. Bourdieu (2007) discute neste sentido afirmando que as disposições sociais internalizadas individualmente moldam as percepções, os sentimentos e as ações de uma pessoa, o que o mesmo vai chamar de habitus dos indivíduos.

Outra questão que merece atenção no que se refere às comunidades é o afrouxamento das mesmas em relação à intensa propagação tecnológica dos meios de comunicação em tempo real. Algumas pessoas afirmam que as comunidades mudaram muito com o passar do tempo, inclusive no que se refere à participação. "Os celulares estão em todo lugar e com todo mundo! No Japão é mais forte, porque é mais fácil para comprar, tem um serviço melhor! Com isso o povo se afasta um pouco da comunidade! Mas acho que isso é normal nesses tempos de hoje". (Paulo Hinamoto, empresário, 34 anos, 1 de março de 2014).

A comunicação pelos meios tecnológicos é uma importante aliada dos migrantes, entretanto favorece por outro lado a criação de pessoas solitárias mesmo dentro de multidões. Entrar no metrô com seus fones de ouvido escutando uma música ou mesmo assistindo algo nos telefones com as mais diversas funções, não exclui o indivíduo de estar sozinho mesmo recebendo essas comunicações de familiares e amigos. O fato de estar conectado com diversas pessoas de forma virtual cria no migrante uma sensação falsa de que não se está sozinho, mesmo o estando fisicamente. Desta forma os meios de comunicação operam como uma estrutura estruturante na qual o indivíduo está ao mesmo tempo conectado a diversas pessoas e ao mesmo tempo sozinho. Por outro lado, a estrutura estruturante cria também uma sensação de pertencimento ao local de origem que auxilia na dor da separação pela imigração. Esta sensação acaba por se tornar uma rotina da vida dos nikkeis que em sua maioria trabalha por extensas horas, não tendo contato com outras pessoas e criando assim uma sociabilidade apenas virtual e não física. Putnam 
(2002) expõe que a tecnologia não somente influencia nas faltas diante os trabalhos comunitários e suas iniciativas como também na própria sociabilização com amigos, vizinhos e parentes.

\section{Considerações Finais}

O presente artigo se propôs a discutir como questões sobre a comunicação de migrantes de dois grupos identitários distintos e em momentos históricos diversos se assemelham na função de interligação e ponte imaginária entre a sociedade de origem e a sociedade de acolhimento. Os meios de comunicação são de fato, como afirma Bourdieu, uma estrutura estruturada para se perceber a estrutura estruturante das sociedades. A partir desses meios de comunicação analisados no artigo foi possível delinear a forma de acolhida e a identidade dos imigrantes advindos da imigração italiana no final do século XIX para São Carlos - SP como da migração e imigração japonesa para São Gotardo - MG no final do século XX, e os dekasseguis de São Gotardo no Japão no início do século XXI.

O Brasil não mais recebe imigrantes apenas, tal como fora visto em outros momentos história, mas agora também envia emigrantes para diversos partes do mundo. Dentre estes emigrantes, estão os nipo-brasileiros que viram na terra dos seus antepassados o lugar para alcançar seus objetivos, seja ter uma vida melhor ou mesmo angariar quantias para investir no Brasil. Ao migrarem estes nipo-brasileiros perpassam por diversas transformações culturais que de certa forma constrói uma nova identidade híbrida entre as culturas brasileira e japonesa, marcando de maneira singular este fenômeno migrante brasileiro.

Por fim e não menos importante, este trabalho veio discutir sobre o tema migrante mas principalmente com novas reflexões teóricas e características que de certa maneira propiciam o reconhecimento da identidade daqueles envolvidos. Debruçar sobre o uso e a forma de comunicação das comunidades migrantes é um viés pouco usual que propicia um conhecimento do cotidiano do migrante negligenciado pelas fontes oficiais e 
impossível de ser alcançado por elas. Tanto os jornais como as cartas para o século XIX ou os novos adventos tecnológicos do século $X X$ oferecem aos imigrantes um contato com seus familiares, amigos, e sua sociedade de origem, contribuindo para a hibridez cultural e a sua sociabilidade.

\section{Referências}

BELTRAO, K. I.; SUGAHARA, S. Permanentemente temporário: dekasseguis brasileiros no Japão. Revista Brasileira de Estudos de População, São Paulo, v. 23, n. 1, jun. 2006. Disponível em: $<$ http://www.scielo.br/scielo.php?script=sci_arttext\&pid=\$010230982006000100005\&lng=en\&nrm=isso>. Acesso em: 20 jul. 2016.

BÉRGSON, Henri. Matéria e memória. Ensaio sobre a relação do corpo com o espírito. São Paulo: Martins Fontes, 1999.

BOURDIEU, Pierre. A distinção: crítica social do julgamento. São Paulo: EdUSP; Porto Alegre: Zouk, 2007.

BOURDIEU, Pierre. O poder simbólico. Lisboa: Difel, 1989.

BOURDIEU, Pierre. Razões práticas: sobre a teoria da ação. Oeiras: Celta, 2008.

CANCLINI, N. G. A globalização imaginada. São Paulo: lluminuras, 2007.

CANO, Wilson. Padrões diferenciados das principais regiões cafeeiras (1850-1930). Revista Estudos Econômicos, São Paulo, v. 15, n. 2, p. 291-306, maio/ago. 1985.

CINTRA, Rosana. Experiências da imigração italiana no interior paulista: imigração, trajetórias e adaptação. In: ENCONTRO REGIONAL DE HISTÓRIA, 20., Franca. História e Liberdade. Franca: UNESP, 2010. COSTA, Emília Viotti da. Da monarquia a república: momentos decisivos. 7.ed. São Paulo: Brasiliense, 1999. 
DIÁRIO DE SÃO CARLOS. São Carlos, 11 jan. 1890.

DIÁRIO DE SÃO CARLOS. São Carlos, 2 mar. 1890.

DIÁRIO DE SÃO CARLOS. São Carlos, 22 maio 1890.

DIÁRIO DE SÃO CARLOS. São Carlos, 25 fev. 1891.

FAUSTO, B. História do Brasil. 2. ed. São Paulo: EdUSP, 1995.

FRANZINA, Emilio. Merica! Merica! Emigrazione e colonizzazione nelle lettere dei contadini veneti e friulani in America Latina, 1876-1902. Verona: Cierre, 1994.

KAWAMURA, L. Brasileiros no Japão: direitos e cidadania. In: HASHIMOTO, F. et al. Cem anos da imigração japonesa: história, memória e arte. São Paulo: UNESP, 2008.

KODAMA, Kodama; SAKURAI, Célia. Episódios da imigração: um balanço de 100 anos. In: IBGE. Resistência \& integração: 100 anos de imigração japonesa no Brasil. Centro de Documentação e Disseminação de Informações. Rio de Janeiro: IBGE, 2008.

LESSER, Jeffrey. How the japanese diaspora in Brazil became the brazilian diaspora in Japan. In: KNOTT, Kim; MCLOUGHLIN, Sean. Diasporas: concepts, intersections, identities. London: Zed Books, 2010.

O POPULAR. São Carlos, 25 de novembro de 1894.

ORDEM E PROGRESSO. São Carlos, 8 de março de 1895.

ORDEM E PROGRESSO. São Carlos, 27 de abril de 1895.

PUTNAM, Robert; GOSS, Kristin. Introduction. In: PUTNAM, Robert (Org.). Democracies in flux. The evolution of social capital in contemporary societies. New York: Oxford University Press, 2002. 
SAKURAI, Célia. Os japoneses. 2. ed. São Paulo: Contexto, 2008.

SANTANA, Luiz Otavio Costa. São Gotardo - MG. Estudo sobre a presença nipo-descendente no Cerrado Mineiro. 2015. Dissertação (Mestrado em Ciências Sociais)- Programa de Pós Graduação em Ciências Sociais, Universidade Federal de Uberlândia, 2015.

SASAKI, E. A imigração para o Japão. Estudos Avançados, São Paulo, v. 20 , n. 57 , ago. 2006. Disponível em: <http://www.scielo.br/scielo. php?script=sci_arttext\&pid=S0103-40142006000200009\&Ing=en\&nrm =iso>.

SASAKI, L. I. Portal do Cerrado. Belo Horizonte: O Lutador, 2008.

Recebido em julho de 2016. Aprovado em janeiro de 2017. 